\title{
A novel Brönsted-Lewis acidic heteropoly organic-inorganic salt: preparation and catalysis for rosin dimerization
}

\author{
Bing Yuan ${ }^{1,2}$, Congxia Xie ${ }^{1 *}$, Fengli Yu ${ }^{1}$, Xiaoying Yang ${ }^{1}$, Shitao Yu ${ }^{3}$, Jianling Zhang ${ }^{2}$ and Xiaobing Chen ${ }^{1}$
}

\begin{abstract}
A novel Brönsted-Lewis acidic heteropoly organic-inorganic salt has been prepared via the replacement of protons in neat phosphotungstic acid with both organic and metal cations. This hybrid catalyst, $\mathrm{Sm}_{0.33}[\mathrm{TEAPS}]_{2} \mathrm{PW}_{12} \mathrm{O}_{40}$ exhibited satisfactory performance in the dimerization of rosin to prepare polymerized rosin Under optimum conditions (15.0 g rosin and $5.0 \mathrm{~g} \mathrm{Sm}{ }_{0.33}[\text { TEAPS }]_{2} \mathrm{PW}_{12} \mathrm{O}_{40}$ catalyst in $18.0 \mathrm{~mL}$ toluene at $90^{\circ} \mathrm{C}$ for $10 \mathrm{~h}$ ), a polymerized rosin product with a softening point of $120.1^{\circ} \mathrm{C}$ was obtained. In addition, the $\mathrm{Sm}_{0.33}[\mathrm{TEAPS}]_{2} \mathrm{PW}{ }_{12} \mathrm{O}_{40}$ catalyst maintains excellent catalytic performance over five recycles.
\end{abstract}

\section{Background}

Polymerized rosin has a higher softening point, lighter color, and better stability than rosin, and is harder to oxidize. It is a key ingredient in oil paints, printing ink, adhesives, perfume, and more (Cheng et al. 1996; Chen 1992). The industrial preparation of polymerized rosin, employing aqueous mineral acids such as $\mathrm{H}_{2} \mathrm{SO}_{4}$ or $\mathrm{ZnCl}_{2} / \mathrm{HCl}$, suffers from various shortcomings, including corrosion, pollution, and difficult recovery. Some environmentally friendly catalysts, such as solid superacids (Luo and Wu 1999; Gao et al. 2007), have been used to realize the clean polymerization of rosin. However, despite their superior separation, solid superacids exhibit insufficient recycling performance due to their uneven and vulnerable active components.

Acid-functionalized ionic liquids, a class of catalyst with the advantages of both aqueous and solid acids, have been applied successfully in many acid-catalyzed reactions (Paun et al. 2008; Fang et al. 2008; Hoang et al. 2005), including the polymerization of rosin (Liu et al. 2005, 2008). Abietic-type resin acids in gum rosin, which contain conjugated double bonds, undergo

\footnotetext{
*Correspondence: xiecongxia@126.com

1 State Key Laboratory Base of Eco-Chemical Engineering, College of Chemistry and Molecular Engineering, Qingdao University of Science and Technology, Qingdao 266042, China

Full list of author information is available at the end of the article
}

polymerization readily, but fir-type resin acids, having more steric hindrance, cannot. Brönsted acids are generally considered more apt to promote the isomerization of fir-type resin acids towards abietic-type resin acids (Scheme 1), while Lewis acids favor the dipolymerization of abietic-type resin acids (Scheme 2) (Cheng et al. 1996). As a result, acid catalysts comprising both Brönsted and Lewis acidity would exhibit a more outstanding catalytic performance in the preparation of polymerized rosin. We previously synthesized (3-sulfonic acid)-propyl-3-methylimidazoliume (and triethylammonium) chlorozincates and demonstrated their good catalytic efficiency and recycling performance in the polymerization of rosin, which can be attributed to the Brönsted-Lewis acidity of the ionic liquids and liquid-liquid two-phase process (Liu et al. 2008, 2009). However, using these catalysts is inconvenient due to their lengthy synthetic cycles and high viscosity. Most importantly, the Lewis acidity of the metal chlorides in the anions would be difficult to maintain due to stability issues, similar to aluminum chloride acid salt ionic liquids.

For the past few years, types of heteropoly organic salt catalytic materials have called attention for their potential water tolerance, acidity and self-separation performance (Leng et al. 2009a, b, 2012; Li et al. 2011, 2014; Shimizu et al. 2009; Sun et al. 2012; Zhou et al. 2014). It has been found that heteropoly anions with high charge numbers 


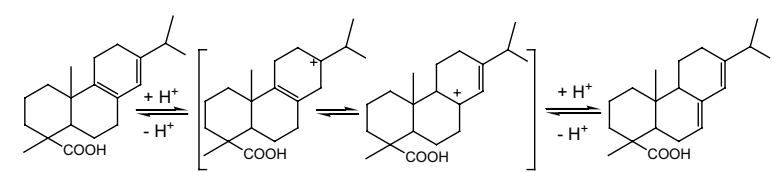

Scheme 1 The isomerization of fir-type resin acids towards abietictype resin acids

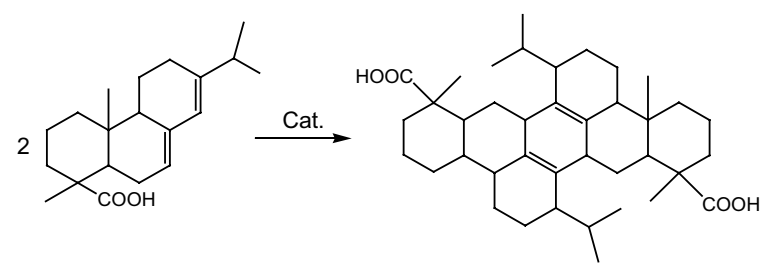

Scheme 2 The dipolymerization of abietic-type resin acids

in these materials lead to higher melting points than conventional ionic liquids (Yuan et al. 2014). Furthermore, based on the high charge numbers of heteropoly anions, sulfated organic cations with Brönsted acidity and metal cations with Lewis acidity can act together as counterions to heteropoly anions, establishing novel BrönstedLewis acidic heteropoly organic-inorganic salts (Yu ST 2013). Herein, we report a heteropoly organic-inorganic catalyst, $\mathrm{Sm}_{0.33}$ [TEAPS $]_{2} \mathrm{PW}_{12} \mathrm{O}_{40}$, with Brönsted-Lewis acidity, which has different performances for melting point, solubility and acidity with both heteropoly compounds and ionic liquids. Moreover, the dimerization of rosin catalyzed by $\mathrm{Sm}_{0.33}[\mathrm{TEAPS}]_{2} \mathrm{PW}_{12} \mathrm{O}_{40}$ as a solid acid has been carried out to achieve an environmentally friendly process for polymerized rosin.

\section{Experimental}

\section{Materials and methods}

Analytical grade $\mathrm{H}_{3} \mathrm{PW}_{12} \mathrm{O}_{40}$ was dried at $180{ }^{\circ} \mathrm{C}$. All other chemicals were of analytical grade and used without further purification. The ${ }^{1} \mathrm{H}-\mathrm{NMR}$ spectra of the catalyst and intermediates were recorded with a $500 \mathrm{MHz}$ Bruker spectrometer in $\mathrm{D}_{2} \mathrm{O}$. FT-IR spectra for catalyst samples (the Py-IR sample was mixed with pyridine (2:1, $v / v$ ) for $24 \mathrm{~h}$ prior to measurement) on $\mathrm{KBr}$ discs were recorded on a Nicolet iS10 FT-IR instrument. Melting points were measured using a conventional method on an X-4 type micro melting point apparatus. TG analysis was performed with a NETZSCH-TG 209 F1 Libra instruments in dry $\mathrm{N}_{2}$ at a heating rate of $20^{\circ} \mathrm{C} / \mathrm{min}$ from 30 to $800^{\circ} \mathrm{C}$.

The acidity of the prepared catalysts was determined by potentiometric titration (Shi and Pan 2008; Vazquez et al. 2000). A mixture containing the sample $(0.5 \mathrm{~g})$ and acetonitrile $(30 \mathrm{~mL})$ was mixed at the stable potential before being titrated with $n-\mathrm{C}_{4} \mathrm{H}_{9} \mathrm{NH}_{2}$ solution $(0.05 \mathrm{~mol} / \mathrm{L}$ in acetonitrile). The initial and jump potential values were measured by a $\mathrm{pH}$ meter to identify the acid strength and total acid amount in catalyst samples.

\section{Catalysts}

Contrastive catalyst, [TEAPS $]_{3} \mathrm{PW}_{12} \mathrm{O}_{40}$ and $\mathrm{H}_{2}$ [TEAPS] $\mathrm{PW}_{12} \mathrm{O}_{40}$, were prepared according to the literature (Leng et al. 2009b). Analogously, equimolar triethylamine and 1,3-propanesultone $(0.10 \mathrm{~mol})$ were dissolved in $80 \mathrm{~mL}$ ethyl acetate and stirred at $50{ }^{\circ} \mathrm{C}$ for $24 \mathrm{~h}$ under nitrogen atmosphere. The obtained white precipitate, 3-(triethylammonio)propane sulfonate, was filtered, washed with ethyl acetate and dried at $100{ }^{\circ} \mathrm{C}$ for $6 \mathrm{~h}$. Next, a solution of intermediate 3-(triethylammonio)propane sulfonate $(0.008 \mathrm{~mol})$ and $\mathrm{Sm}\left(\mathrm{NO}_{3}\right)_{3} \cdot 6 \mathrm{H}_{2} \mathrm{O}(0.0013 \mathrm{~mol})$ in water was dropped into another aqueous solution of $\mathrm{H}_{3} \mathrm{PW}_{12} \mathrm{O}_{40}(0.004 \mathrm{~mol})$. The mixture was stirred at room temperature for $24 \mathrm{~h}$, distilled to remove water, and washed with ethyl acetate. Finally, the obtained $\mathrm{Sm}_{0.33}$ [TEAPS $]_{2} \mathrm{PW}_{12} \mathrm{O}_{40}$ solid was dried in a vacuum at $80{ }^{\circ} \mathrm{C}$ for $6 \mathrm{~h}$ (Leng et al. 2009b; Ramesh Kumar et al. 2012). Catalyst $\mathrm{Sm}_{0.66}[$ TEAPS $] \mathrm{PW}_{12} \mathrm{O}_{40}$ was prepared by a similar method to that outlined above, using alternative materials proportion.

\section{Dimerization of rosin}

In batch experiments, heteropoly organic-inorganic salt catalyst $(5.0 \mathrm{~g})$ was added to a round-bottomed flask contained toluene $(18.0 \mathrm{~mL})$ and dissolved rosin $(15.0 \mathrm{~g})$. The resulting reaction mixture was stirred vigorously at $90{ }^{\circ} \mathrm{C}$ for $10 \mathrm{~h}$ and then cooled to room temperature. The solid catalyst was removed by centrifugation and directly reused without further treatment. The reaction solution, from which the toluene solvent had been separated, was distilled under low pressure $(2 \mathrm{mmHg})$ at $260-270{ }^{\circ} \mathrm{C}$ (system temperature) and $180-210{ }^{\circ} \mathrm{C}$ (steam outlet temperature) for $30 \mathrm{~min}$ to remove low softening point materials, such as rosinol and some unpolymerized rosin, and obtain the polymerized rosin product. The ring and ball softening points of the products were determined by SYD-2806G numerical control asphalt softening point tester.

\section{Results and discussion}

\section{Characterization of hybrid catalysts}

Similar patterns were observed in the ${ }^{1} \mathrm{H}-\mathrm{NMR}(500 \mathrm{MHz}$, $\left.\mathrm{D}_{2} \mathrm{O}\right)$ spectra of $\mathrm{Sm}_{0.33}$ [TEAPS] ${ }_{2} \mathrm{PW}_{12} \mathrm{O}_{40}, \mathrm{Sm}_{0.66}$ [TEAPS] $\mathrm{PW}_{12} \mathrm{O}_{40}$, [TEAPS $]_{3} \mathrm{PW}_{12} \mathrm{O}_{40}, \mathrm{H}_{2}$ [TEAPS] $\mathrm{PW}_{12} \mathrm{O}_{40}$ and their intermediate 3-(triethylammonio)propane sulfonate $[\delta 1.17(\mathrm{t}, 9 \mathrm{H}), 2.02(\mathrm{~m}, 2 \mathrm{H}), 2.87(\mathrm{t}, 2 \mathrm{H}), 3.23$ 
$(\mathrm{m}, 8 \mathrm{H})]$, which supported the correct structure of the organic cations (Leng et al. 2009b). The FT-IR spectrum of $\mathrm{Sm}_{0.33}$ [TEAPS $]_{2} \mathrm{PW}_{12} \mathrm{O}_{40}$ is shown in Fig. 1, in comparison with those of reused $\mathrm{Sm}_{0.33}$ [TEAPS ${ }_{2} \mathrm{PW}_{12} \mathrm{O}_{40}$, $\mathrm{H}_{2}$ [TEAPS] $\mathrm{PW}_{12} \mathrm{O}_{40}$, and neat $\mathrm{H}_{3} \mathrm{PW}_{12} \mathrm{O}_{40}$. It was observed that $\mathrm{Sm}_{0.33}[\mathrm{TEAPS}]_{2} \mathrm{PW}_{12} \mathrm{O}_{40}$, reused $\mathrm{Sm}_{0.33}[\text { TEAPS }]_{2} \mathrm{PW}_{12} \mathrm{O}_{40}$, and $\mathrm{H}_{2}$ [TEAPS $] \mathrm{PW}_{12} \mathrm{O}_{40}$ had four featured peaks similar to those of $\mathrm{H}_{3} \mathrm{PW}_{12} \mathrm{O}_{40}[1080$ $(\mathrm{P}-\mathrm{O}), 984(\mathrm{~W}=\mathrm{O}), 889\left(\mathrm{~W}-\mathrm{O}_{\mathrm{b} 1}-\mathrm{W}\right)$ and $806 \mathrm{~cm}^{-1}$ $\left.\left(\mathrm{W}-\mathrm{O}_{\mathrm{b} 2}-\mathrm{W}\right)\right]$, which were assigned to the Keggin structure. Different degree shifts (around 1079, 981, 897 and $806 \mathrm{~cm}^{-1}$ ) and lower peak intensities compared to $\mathrm{H}_{3} \mathrm{PW}_{12} \mathrm{O}_{40}$ confirmed that the formation of new heteropoly organic-inorganic salts had been achieved without breaking the Keggin structure. In addition, featured peaks at $2987,1485,1394,1127$ and $1156 \mathrm{~cm}^{-1}$ of TEAPS ${ }^{+}$(Liu et al. 2008; Leng et al. 2009b) also appeared in the spectra of the hybrid catalysts. The above results indicated that both TEAPS ${ }^{+}$and $\mathrm{PW}_{12} \mathrm{O}_{40}{ }^{3-}$ were combined in all of the hybrid catalysts. Moreover, the Py-IR spectrum illustrated in Fig. 2 indicates the existence of both Brönsted acid sites $\left(1538 \mathrm{~cm}^{-1}\right)$ and Lewis acid sites $\left(1456 \mathrm{~cm}^{-1}\right)$ in $\mathrm{Sm}_{0.33}$ [TEAPS $]_{2} \mathrm{PW}_{12} \mathrm{O}_{40}$, which proved the presence of Brönsted-Lewis acidity derived from organic cations and $\mathrm{Sm}^{3+}$.

Table 1 shows the basic properties of the designed $\mathrm{Sm}_{0.33}[\text { TEAPS }]_{2} \mathrm{PW}_{12} \mathrm{O}_{40}$ catalyst and similar substances. It was found that the introduction of $\mathrm{Sm}^{3+}$ lead to samples having properties similar to inorganic salts (melting points $>300{ }^{\circ} \mathrm{C}$ ) and quite different to those of heteropoly ionic liquids [TEAPS $]_{3} \mathrm{PW}_{12} \mathrm{O}_{40}$ and neat $\mathrm{H}_{3} \mathrm{PW}_{12} \mathrm{O}_{40}$. Concerning acidity, a lower acid strength and total acid amount was observed in hybrid samples with metal cations compared with [TEAPS] ${ }_{3} \mathrm{PW}_{12} \mathrm{O}_{40}$ and $\mathrm{H}_{3} \mathrm{PW}_{12} \mathrm{O}_{40}$. Besides, the poor solubility of $\mathrm{Sm}_{0.33}$ [TEAPS ${ }_{2} \mathrm{PW}_{12} \mathrm{O}_{40}$ in both water and organic solvent toluene forced it to be used as a solid catalyst in the prospective reaction.

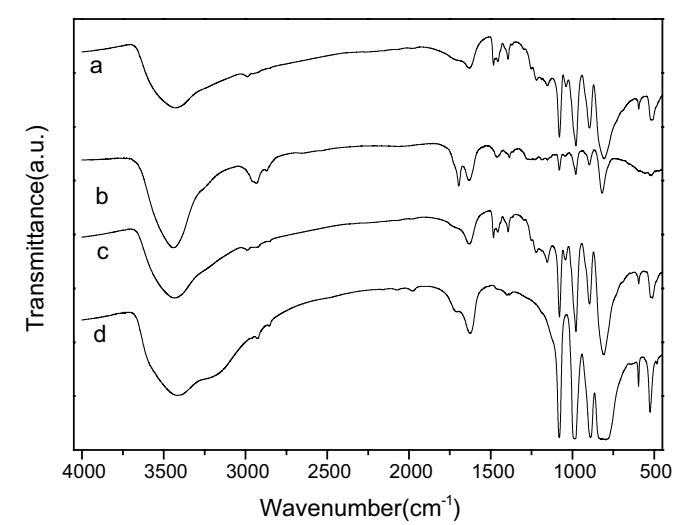

Fig. 1 FT-IR spectra for hybrid catalysts. a Sm 0.33 TTEAPS $]_{2} \mathrm{PW}_{12} \mathrm{O}_{40}$. $b$ Reused $\mathrm{Sm}_{0.33}[\text { TEAPS }]_{2} \mathrm{PW}_{12} \mathrm{O}_{40} \cdot \mathrm{CH}_{2}$ [TEAPS $] \mathrm{PW}_{12} \mathrm{O}_{40} \cdot d \mathrm{H}_{3} \mathrm{PW}_{12} \mathrm{O}_{40}$

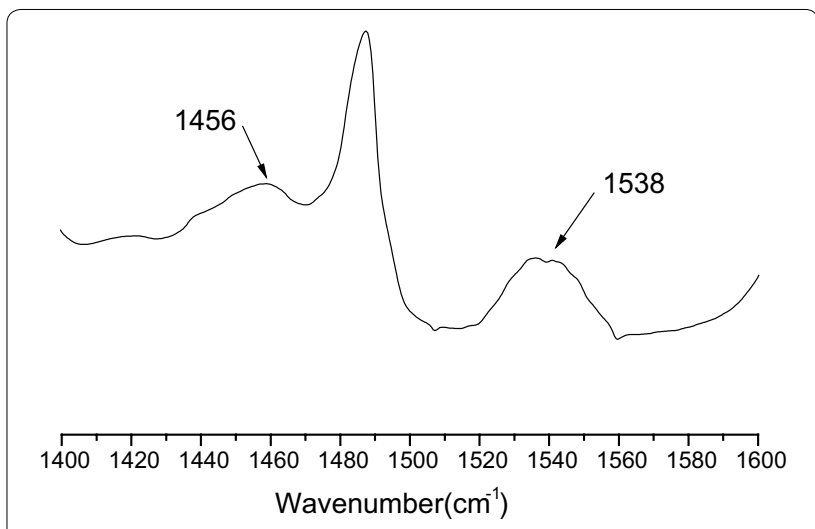

Fig. 2 Py-IR spectra for $\mathrm{Sm}_{0.33}[\mathrm{TEAPS}]_{2} \mathrm{PW}_{12} \mathrm{O}_{40}$

Figure 3 shows that $\mathrm{Sm}_{0.33}$ [TEAPS $]_{2} \mathrm{PW}_{12} \mathrm{O}_{40}$ loses unbound and crystal water (calculated weight loss: $2.66 \%$ ) between 30 and $200{ }^{\circ} \mathrm{C}$. Moreover, the decomposition peaks of the organic cation matrix and sulfonic group were observed at 290 and $420^{\circ} \mathrm{C}$, respectively. The TG profile indicated that $\mathrm{Sm}_{0.33}$ [TEAPS $]_{2} \mathrm{PW}_{12} \mathrm{O}_{40}$ was quite stable below $200{ }^{\circ} \mathrm{C}$.

\section{Catalytic performances of $\mathrm{Sm}_{0.33}$ [TEAPS ${ }_{2} \mathrm{PW}_{12} \mathrm{O}_{40}$ in the dimerization of rosin}

Table 2 shows that a product with a similar softening point and acid value to gum rosin was obtained without catalyst. This was also observed in the reaction catalyzed by $\mathrm{H}_{3} \mathrm{PW}_{12} \mathrm{O}_{40}$, having high acid strength, indicating that Brönsted acidity derived from the antiprotons of $\mathrm{H}_{3} \mathrm{PW}_{12} \mathrm{O}_{40}$ had almost no effect on the promotion of rosin dimerization under the solid acid catalyst conditions. In addition, the Brönsted acidity derived from sulfonic acid groups in the organic cations alone did not have the necessary catalytic ability for dimerization, resulting in a product with $103.7{ }^{\circ} \mathrm{C}$ softening point. When both $\mathrm{Sm}^{3+}$ and organic cations containing sulfonic acid group [TEAPS $^{+}$were co-introduced to the structure of a heteropoly compound, Brönsted-Lewis double acidity (Fig. 2) and, consequently, a high catalytic performance were achieved (Table 2). In particular, a favorable polymerized rosin product with a softening point of $120.1^{\circ} \mathrm{C}$ [higher than the result of Reference Liu et al. (2009) but lower than that of reference Liu et al. (2008)] was obtained by $\mathrm{Sm}_{0.33}[\text { TEAPS }]_{2} \mathrm{PW}_{12} \mathrm{O}_{40}$, a hybrid catalyst with proper Brönsted and Lewis acidity proportions. However, the Lewis acid sites of $\mathrm{Sm}^{3+}$ in $\mathrm{Sm}_{0.33}[\text { TEAPS }]_{2} \mathrm{PW}_{12} \mathrm{O}_{40}$ were surrounded by more bulky phosphotungstic acid radicals and organic cations than those of $\mathrm{Sm}_{0.66}$ [TEAPS] $\mathrm{PW}_{12} \mathrm{O}_{40}$ and the Brönsted-Lewis Acidic ionic liquids reported in References (Liu et al. 2008, 2009). For this reason, the decarboxylated conjugated resin acids with lower steric hindrance attached more easily to $\mathrm{Sm}^{3+}$ 
Table 1 Properties of hybrid catalysts

\begin{tabular}{|c|c|c|c|c|c|c|}
\hline \multirow[t]{2}{*}{ Samples } & \multirow[t]{2}{*}{ Feature } & \multirow{2}{*}{$\begin{array}{l}\text { Melting } \\
\text { point }\left({ }^{\circ} \mathrm{C}\right)\end{array}$} & \multicolumn{2}{|c|}{ Solubility $\left(25^{\circ} \mathrm{C}\right)$} & \multirow{2}{*}{$\begin{array}{l}\text { Acid strength } \\
(\mathrm{mV})\end{array}$} & \multirow{2}{*}{$\begin{array}{l}\text { Total acid } \\
\text { amount }(\mathrm{mmol} / \mathrm{g})\end{array}$} \\
\hline & & & Water & Toluene & & \\
\hline $\mathrm{Sm}_{0.33}[\text { TEAPS }]_{2} \mathrm{PW}_{12} \mathrm{O}_{40}$ & White powder & $>300$ & Almost not & Not & 679 & 0.428 \\
\hline $\mathrm{Sm}_{0.66}\left[\right.$ TEAPS]PW ${ }_{12} \mathrm{O}_{40}$ & White powder & $>300$ & Almost not & Not & 676 & 0.148 \\
\hline$[\mathrm{TEAPS}]_{3} \mathrm{PW}_{12} \mathrm{O}_{40}$ & White powder & 178 & Almost not & Not & 718 & 0.873 \\
\hline $\mathrm{H}_{3} \mathrm{PW}_{12} \mathrm{O}_{40}$ & Faint yellow/white crystal & 95 & Yes & Not & 702 & 0.791 \\
\hline
\end{tabular}

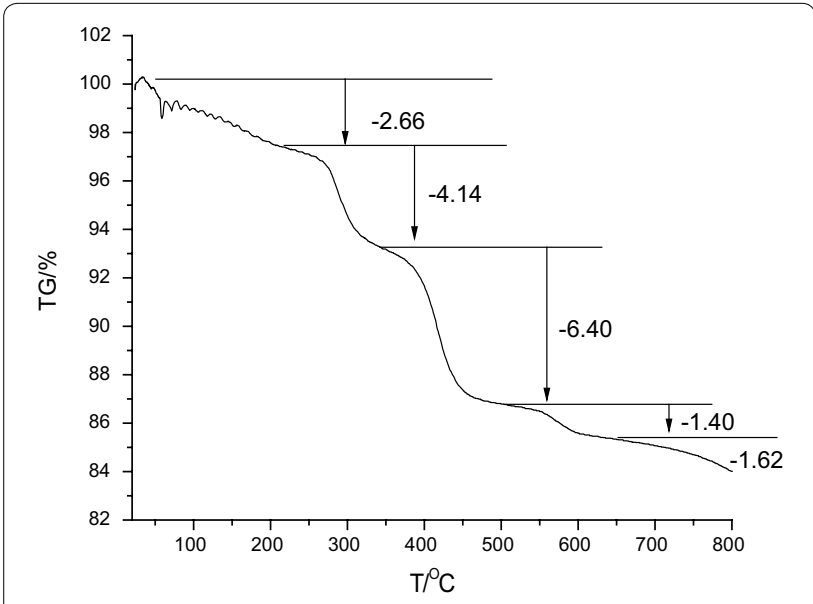

Fig. $3 \mathrm{TG}$ profiles of $\mathrm{Sm}_{0.33}[\mathrm{TEAPS}]_{2} \mathrm{PW}_{12} \mathrm{O}_{40}$

Table 2 Catalytic dimerization performance of hybrid catalysts

\begin{tabular}{lcc}
\hline Catalysts & $\begin{array}{l}\text { Softening } \\
\text { point }\left({ }^{\circ} \mathbf{C}\right)\end{array}$ & Acid value $(\mathbf{m g} / \mathbf{g})$ \\
\hline Gum rosin & 80.4 & 164.0 \\
Blank & 88.3 & 165.0 \\
$\mathrm{H}_{3} \mathrm{PW}_{12} \mathrm{O}_{40}$ & 86.5 & 137.8 \\
{$\left[\right.$ TEAPS ${ }_{3} \mathrm{PW}_{12} \mathrm{O}_{40}$} & 103.7 & 134.7 \\
$\mathrm{Sm}_{0.66}\left[\right.$ TEAPS $\mathrm{PW}_{12} \mathrm{O}_{40}$ & 111.9 & 147.9 \\
$\mathrm{Sm}_{0.33}\left[\right.$ TEAPS ${ }_{2} \mathrm{PW}_{12} \mathrm{O}_{40}$ & 120.1 & 111.8 \\
\hline
\end{tabular}

Reaction conditions: catalyst $5.0 \mathrm{~g}$, rosin $15 \mathrm{~g}$, toluene $18 \mathrm{~mL}, 90^{\circ} \mathrm{C}, 10 \mathrm{~h}$

Table 3 Catalytic reusability of $\mathrm{Sm}_{0.33}\left[\right.$ TEAPS ${ }_{2} \mathrm{PW}_{12} \mathrm{O}_{40}$ for the rosin dimerization

\begin{tabular}{lll}
\hline Catalyst recycle times & Softening point $\left({ }^{\circ} \mathbf{C}\right)$ & Acid value $(\mathbf{m g} / \mathbf{g})$ \\
\hline 0 & 120.1 & 111.8 \\
1 & 114.3 & 125.8 \\
2 & 115.0 & 120.3 \\
3 & 126.1 & 124.5 \\
4 & 120.4 & 93.7 \\
5 & 120.3 & 96.0 \\
\hline
\end{tabular}

Reaction conditions: catalyst $5.0 \mathrm{~g}$, rosin $15 \mathrm{~g}$, toluene $18 \mathrm{~mL}, 90^{\circ} \mathrm{C}, 10 \mathrm{~h}$ than the conjugated resin acids without decarboxylation, which accounted for the lower acid value of products obtained from the $\mathrm{Sm}_{0.33}$ [TEAPS $]_{2} \mathrm{PW}_{12} \mathrm{O}_{40}$ catalyst (Liu et al. 2008, 2009).

The solid catalyst, $\mathrm{Sm}_{0.33}[\mathrm{TEAPS}]_{2} \mathrm{PW}_{12} \mathrm{O}_{40}$, precipitated to the bottom of the reactor after the reaction, allowing separation from the solution via simple centrifugation. The separated $\mathrm{Sm}_{0.33}$ [TEAPS $]_{2} \mathrm{PW}_{12} \mathrm{O}_{40}$ catalyst could be reused several times without treatment (see Table 3). The polymerized rosin products with high softening points (above $120{ }^{\circ} \mathrm{C}$ ) were obtained even after reusing the catalyst five times, which was attributed to the concerted catalysis of Brönsted and Lewis acid sites and their covalent or ionic bonding pattern in the body of the catalyst in the solid-liquid catalytic system. The FT-IR spectrum of reused $\mathrm{Sm}_{0.33}[\mathrm{TEAPS}]_{2} \mathrm{PW}_{12} \mathrm{O}_{40}$, shown in Fig. 2, also indicates that no apparent structural change had taken place in the catalyst during use.

\section{Conclusion}

A novel heteropoly organic-inorganic salt with Brönsted-Lewis double acidity, $\mathrm{Sm}_{0.33}$ [TEAPS $]_{2} \mathrm{PW}_{12} \mathrm{O}_{40}$, was prepared via the replacement of protons in neat phosphotungstic acid with both organic cations containing sulfonic acid groups and metal $\mathrm{Sm}^{3+}$ cations. As a solid acid catalyst, this environmentally benign BrönstedLewis double acidic hybrid enables an effective catalytic performance in the dimerization of rosin to afford polymerized rosin products with a softening point above $115^{\circ} \mathrm{C}$. Moreover, the catalyst also exhibited reasonable reuseability, demonstrated by a five-run recycling test.

\section{Authors' contributions}

BY made the study desighs, did the data analysis, and drafted the manuscript. CXX, FLY, STY and JLZ participated in the design and coordination of the study and helped to draft the manuscript, $X Y Y$ and $X B C$ participated in the acquisition of data. All authors read and approved the final manuscript.

\section{Author details}

${ }^{1}$ State Key Laboratory Base of Eco-Chemical Engineering, College of Chemistry and Molecular Engineering, Qingdao University of Science and Technology, Qingdao 266042, China. ${ }^{2}$ Beijing National Laboratory for Molecular Sciences (BNLMS), Beijing 100190, China. ${ }^{3}$ College of Chemical Engineering, Qingdao University of Science and Technology, Qingdao 266042, China. 


\section{Acknowledgements}

The financial support provided for this research by the "National Natural Science Foundation of China" (31470595, 31270615 and 21106074), "Opening Foundation of Beijing National Laboratory for Molecular Sciences" (20140141) and "The Taishan Scholar Program of Shandong" is gratefully acknowledged.

\section{Competing interests}

The authors declare that they have no competing interests.

Received: 17 November 2015 Accepted: 4 April 2016

Published online: 14 April 2016

\section{References}

Chen GF (1992) Development in the field of rosin chemistry and its implications in coatings. Prog Org Coat 20:139-167

Cheng Z, Zhang JK, Jin Q (1996) Natural resin production technology. China Forestry Publishing House, Beijing, pp 20-25

Fang D, Cheng J, Gong K, Shi QR, Liu ZL (2008) Synthesis of coumarins via bechmann reaction in water catalyzed by acyclic acidic ionic liquids. Catal Lett 121:255-259

Gao HC, Yu ST, Liu FS, Xie CX, Li L (2007) Studies on synthesis of polymerized rosin catalyzed by mesoporous molecular sieves under supercritical carbon dioxide conditions. Chem Ind For Prod 27:72-76

Hoang P, Samira Z, Michel B (2005) An improved greener esterification of fatty alcohols using a renewable acid-ionic liquid cuple as catalyst-solvent. Synth Commun 34:2085-2093

Leng Y, Wang J, Zhu DR, Ren XQ, Ge HQ, Shen L (2009a) Heteropolyanionbased ionic liquids: reaction-induced self-separation catalysts for esterification. Angew Chem Int Ed 48:168-171

Leng Y, Wang J, Zhu DR, Wu YJ, Zhao PP (2009b) Sulfonated organic heteropolyacid salts: recyclable green solid catalysts for esterifications. J Mol Catal A 313:1-6

Leng Y, Jiang PP, Wang J (2012) A novel Brønsted acidic heteropolyanion-based polymeric hybrid catalyst for esterification. Catal Commun 25:41-44

Li KX, Chen L, Wang HL, Lin WB, Yang ZC (2011) Heteropolyacid salts as selfseparation and recyclable catalysts for transesterification of trimethylolpropane. Appl Catal A 392:233-237
Li YY, Wu XF, Wu QY, Ding H, Yan WF (2014) Ammonium- and phosphoniumbased temperature control-type polyoxometalate ionic liquids. Dalton Trans 43:13591-13595

Liu SW, Yu ST, Liu FS, Xie CX, Mao CM (2005) Studies on synthesis of polymerized rosin catalyzed by sulfuric acid-ionic liquid. Chem Ind For Prod 25:65

Liu SW, Xie CX, Yu ST, Liu FS (2008) Dimerization of rosin using Brønsted-Lewis acidic ionic liquid as catalyst. Catal Commun 9:2030-2034

Liu SW, Xie CX, Yu ST, Xian M, Liu FS (2009) Brønsted-Lewis acidic ionic liquid: its synthesis and use as the catalyst in rosin dimerization. Chin J Catal 30:401-406

Luo JY, Wu ZM (1999) Studies on synthesis of polymeric rosin catalyzed by solid superacids. Chem Ind For Prod 19:57-62

Paun C, Stere C, Coman SM, Parvulescu VI, Goodrich P, Hardacre C (2008) Acylation of sulfonamines using silica grafted 1-butyl-3-(3-triethoxysilylpropyl)4,5-dihydroimidazolium ionic liquids as catalysts. Catal Today 131:98-103

Ramesh Kumar Ch, Jagadeeswaraiah K, Sai Prasad PS, Lingaiah N (2012) Samarium-exchanged heteropoly tungstate: an efficient solid acid catalyst for the synthesis of glycerol carbonate from glycerol and benzylation of anisole. ChemCatChem 4:1360-1367

Shi J, Pan G (2008) Preparation of 1-butyl-3-methylimidazolium dodecatungstophosphate and its catalytic performance for esterification of ethanol and acetic acid. Chin J Catal 29:629-632

Shimizu K, Furukawa H, Kobayashi N, Itaya Y, Satsuma A (2009) Effects of Brønsted and Lewis acidities on activity and selectivity of heteropolyacidbased catalysts for hydrolysis of cellobiose and cellulose. Green Chem 11:1627-1632

Sun Z, Cheng MX, Li HC, Shi T, Yuan MJ, Wang XH, Jiang ZJ (2012) One-pot depolymerization of cellulose into glucose and levulinic acid by heteropolyacid ionic liquid catalysis. RSC Adv 2:9058-9065

Vazquez P, Pizzio L, Caceres C, Blanco M, Thomas H, Alesso E, Finkielsztein L, Lantano B, Moltrasio G, Aguirre J (2000) Silica-supported heteropolyacids as catalysts in alcohol dehydration reactions. J Mol Catal A 161:223-232

Yuan B, Xie CX, Yu FL, Zhao WS, Liu ZQ, Yu ST, A sort of heteropoly ionic liquid catalysts with both Brönsted and Lewis acidity. ZL 201310299872.8 CN

Yuan B, Zhao WS, Yu FL, Xie CX (2014) Clean benzylation of anisole with benzyl alcohol over recyclable partially sulfonated imidazole-exchanged heteropoly phosphotungstates. Catal Commun 57:89-93

Zhou Y, Chen GJ, Long ZY, Wang J (2014) Recent advances in polyoxometalate-based heterogeneous catalytic materials for liquid-phase organic transformations. RSC Adv 4:42092-42113

\section{Submit your manuscript to a SpringerOpen ${ }^{\circ}$ journal and benefit from:}

- Convenient online submission

- Rigorous peer review

- Immediate publication on acceptance

- Open access: articles freely available online

- High visibility within the field

- Retaining the copyright to your article

Submit your next manuscript at springeropen.com 